\title{
Evaluation of the predictive power of laboratory markers in the diagnosis of acute appendicitis in the elderly
}

\author{
(1) Savas Bayrak, ${ }^{1}$ (i) Cihad Tatar, ${ }^{1}$ (i) Ekrem Cakar, ${ }^{1}$ (i) Sukru Colak, ${ }^{1}$ (i) Mehmet Emin Gunes, ${ }^{2}$

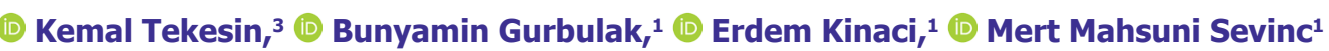 \\ ${ }^{1}$ Department of General Surgery, Istanbul Training and Research Hospital, Istanbul, Turkey \\ ${ }^{2}$ Department of General Surgery, Bakirkoy Sadi Konuk Training and Research Hospital, Istanbul, Turkey \\ ${ }^{3}$ Department of General Surgery, Umraniye Training and Research Hospital, Istanbul, Turkey
}

\begin{abstract}
OBJECTIVE: The aim of this study was to analyze the predictive value of preoperative laboratory findings in acute appendicitis in geriatric patients aged $>65$ years.

METHODS: We enrolled a total of 4121 patients. A retrospective evaluation of the demographic features was made using preoperative laboratory values such as the white blood cell (WBC), neutrophil, and lymphocyte counts; platelet counts; the mean platelet volume and bilirubin values; and postoperative pathological data of the patients from the electronic file system. The neutrophil-to-WBC and neutrophil-to-lymphocyte ratios were calculated. Patients were divided into two groups, as geriatric ( $\geq 65$ years old, $n=140$ ) and non-geriatric ( $<65$ years old, $n=3981$ ).

RESULTS: The white blood cell and lymphocyte counts, and the neutrophil-to-WBC ratio, were significantly higher in the non-geriatric group $(p<0.001, p=0.013$, and $p=0.021$, respectively). The neutrophil and platelet counts were higher in the non-geriatric group, but this difference was not statistically significant $(p=0.073$ and $p=0.072$, respectively). A higher neutrophil-to-lymphocyte ratio was determined in the geriatric group, but the difference was not significant $(p=0.176)$. According to the optimumal cutoff value of $12.11 \times 10^{3} / \mu \mathrm{L}$ for $\mathrm{WBC}$, specificity and sensitivity values of $65.4 \%$ and $57.9 \%$ were calculated, respectively; the AUC value was $0.632 \pm 0.024(p<0.001)$. A receiver operating characteristic $(R O C)$ analysis was used to calculate the optimum cutoff values of neutrophil-to-WBC ratio, lymphocyte, and the mean platelet volume, but the diagnostic accuracy of these tests was inadequate with an AUC of $<0.6$.
\end{abstract}

CONCLUSION: WBC values $>12.11 \times 10^{3} / \mu \mathrm{L}$ were predictive of acute appendicitis in geriatric patients. The other parameters were not predictive, and further studies are required.

Keywords: Acute appendicitis; geriatric patients; laboratory parameters.

Cite this article as: Bayrak S, Tatar C, Cakar E, Colak S, Gunes ME, Tekesin K, et al. Evaluation of the predictive power of laboratory markers in the diagnosis of acute appendicitis in the elderly. North Clin Istanb 2019;6(3):293-301.

A cute appendicitis resulting from inflammation of the appendix is one of the most common clinical situations necessitating an abdominal surgical intervention [1-3]. The incidence of appendicitis is $233: 100,000$, and its lifetime incidence is approximately $7 \%-10 \%[4]$. Ap- pendicitis is often seen in young adults in the second and third decades of life, and its incidence is highest in those aged $10-19$ years. The main management goal is early diagnosis with appropriate and timely surgical procedures. In cases where patients have not sought medical care, the

Received: April 16, 2019 Accepted: May 14, 2019 Online: July 08, 2019

Correspondence: Dr. Savas BAYRAK. Istanbul Egitim ve Arastirma Hastanesi, Genel Cerrahi Klinigi, Istanbul, Turkey.

Tel: +90 5332480409 e-mail: savasbayrak74@gmail.com

(c) Copyright 2019 by Istanbul Provincial Directorate of Health - Available online at www.northclinist.com 
diagnosis may be delayed and difficult [5]. Negative appendectomies have previously been acceptable at a rate of approximately $15 \%$. However, as imaging methods have become increasingly common, this rate has decreased to $<10 \%$ [6]. Clinical approaches to the management of acute appendicitis may be complicated in some patient groups, particularly children, women of reproductive age, and geriatric patients [7].

Acute appendicitis is not rare in geriatric patients; $0.05 \%$ of the geriatric population develops acute appendicitis each year. In developed countries, appendicitis in the geriatric population is even rarer, although it is now becoming more common [8]. Appendicitis has become a significant cause of abdominal pain in older patients. Due to a blunted inflammatory response (such as leukocytosis and cytokine pool), elderly patients generally have a less remarkable history and physical findings [9]. This clinical situation may lead to a delayed diagnosis and increased complication rates, such as perforation on presentation $[10,11]$. Perforation particularly significantly increases morbidity and mortality [12]. Geriatric patients also have a higher tendency for comorbidities, which increases morbidity and mortality rates. They often have other conditions such as diverticulitis or neoplasms that can mimic acute appendicitis. Thus, a broad list should be considered during the differential diagnosis of a geriatric population [13]. Computed tomography can increase the rate of accurate diagnosis [14], and laparoscopic appendectomies offer a shorter hospitalization time and fewer complications in geriatric patients [15-17].

Several studies have evaluated the value of parameters such as preoperative complete blood count $(\mathrm{CBC})$, white blood cell (WBC), neutrophil-to-lymphocyte ratio (NLR), neutrophil percentage (neutrophil/WBC ratio, NWR), the mean platelet volume (MPV), and bilirubin levels in acute appendicitis [18-23]. However, studies investigating the predictive value of laboratory parameters in acute appendicitis in the geriatric population are limited. The aim of this study was to analyze the predictive value of preoperative laboratory findings in acute appendicitis in geriatric patients aged $>65$ years.

\section{MATERIALS AND METHODS}

This study, which was approved by the ethical board of the Istanbul Training and Research Hospital (09/22/2017. 1090), included 4144 patients who applied with open or laparoscopic appendectomy in our clinic between March 2005 and December 2016. Informed consent was obtained from all individual participants included in the study. The data of 23 patients could not be retrieved. Thus, the demographic features and preoperative laboratory values such as WBC, neutrophil, lymphocyte and platelet counts, MPV and bilirubin values, and postoperative histopathological results of 4121 patients were collected from the electronic file system. $\mathrm{CBC}$ and bilirubin were measured with an automated hematology analyzer and chemiluminescence, respectively. The NWR and NLR ratios were calculated. The study included patients aged 15-95 years who were then grouped as $<65$ years or $\geq 65$ years. Patients aged $<15$ years, pregnant patients, and those with chronic liver disease or malignancy were excluded.

\section{Statistical Analysis}

Data analysis used the SPSS 22.0 (IBM Corporation, Armonk, New York, USA) and Medcalc 14 (Acacialaan 22 , B-8400 Ostend, Belgium) programs. The conformity of the univariate data to normal distribution was evaluated using the Shapiro- Wilk test. When comparing two independent groups according to quantitative data, the Mann-Whitney U test was used with the Monte Carlo results. When comparing categorical variables, the Pearson chi-squared exact test was applied. The association between the classification separated by cutoff values calculated according to variables, and real classification was analyzed with a receiver operating characteristic (ROC) curve. Quantitative and categorical variables were shown in the tables as the median range (maximum-minimum) and number ( $\mathrm{n}$ ) and percentage (\%), respectively. Variables were examined at the $95 \%$ confidence interval, and a p-value $<0.05$ was accepted as statistically significant.

\section{RESULTS}

The patients included 1574 (37.98\%) females and 2547 $(62.02 \%)$ males, with a mean age of $34.55 \pm 12.14$ years (median age, 32 years; age range, $15-95$ years). The patients were classified as geriatric ( $\geq 65$ years old) and non-geriatric ( $<65$ years old) groups according to their age. The geriatric group comprised $140(3.4 \%)$ of the total patient group with statistically significantly more females in the geriatric group than the non-geriatric groups ( $\mathrm{p}=0.001)$ (Fig. 1).

Perforation was detected in $24(17.14 \%)$ and 598 $(15.02 \%)$ patients in the geriatric and non-geriatric group, respectively. There is no statistically significant difference between groups in terms of perforation rates.

The WBC mean of 24 patients with perforated ap- 


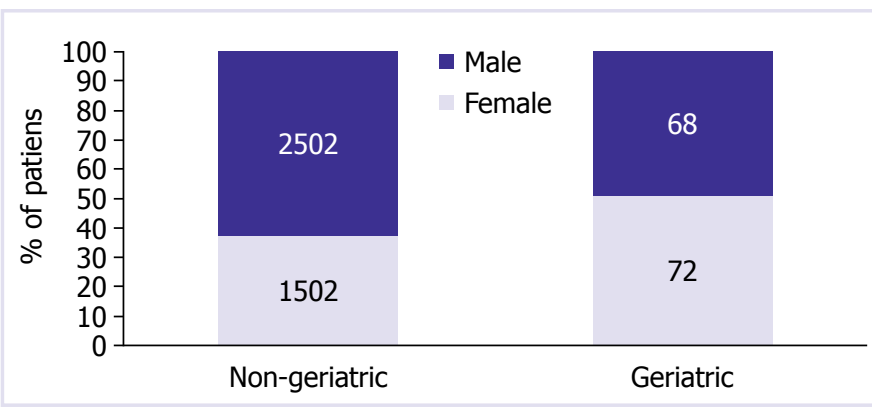

FIGURE 1. Gender differences between the geriatric and nongeriatric groups.

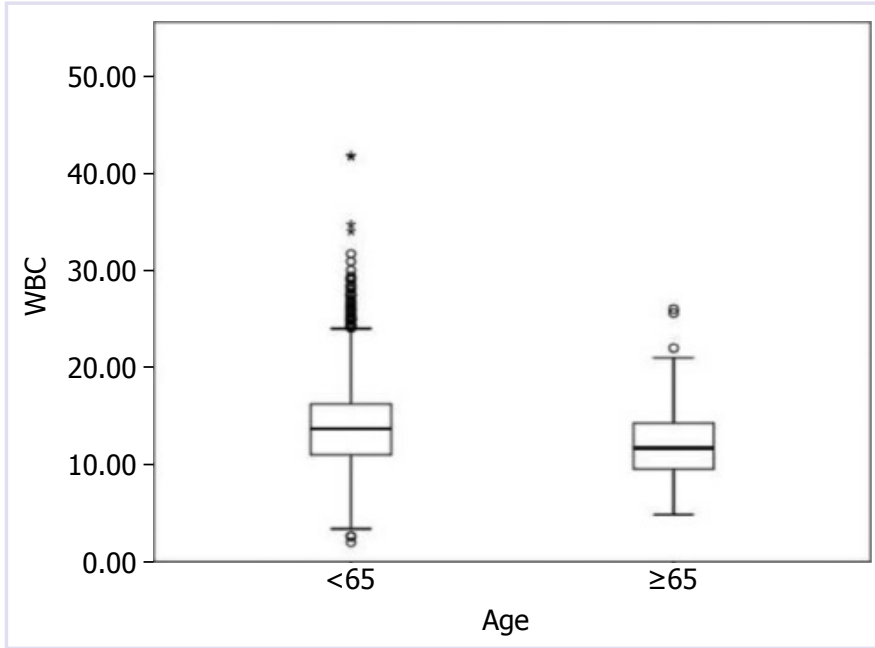

FIGURE2. The comparison of WBC counts between the age groups.

pendicitis in the geriatric group was $13.39 \times 10^{3} / \mu \mathrm{L}$, and the WBC mean of the 598 patients with perforated appendicitis was $16.4 \times 10^{3} / \mu \mathrm{L}$. This analysis shows that there is no statistically significant difference between the geriatric and non-geriatric patients $(\mathrm{p}=0.094)$.

The WBC, lymphocyte counts, and NWR were significantly higher in the non-geriatric group $(p<0.001$, $p=0.013$, and $p=0.021$, respectively). These distributions are shown in Figures 2, 3, and 4. Neutrophil and platelet counts were higher in the non-geriatric group, but this difference was not statistically significant $(\mathrm{p}=0.073$ and $\mathrm{p}=0.072$, respectively). A higher NLR was determined in the geriatric group, but the difference was not significant $(p=0.176)$. The MPV values were increased in geriatric patients $(p=0.036)$. Bilirubin levels of the patients were similar between the age groups $(p=0.797)$. Acute perforated gangrenous appendicitis was determined in $87.47 \%$ of the non-geriatric cases and in $77.14 \%$ of the

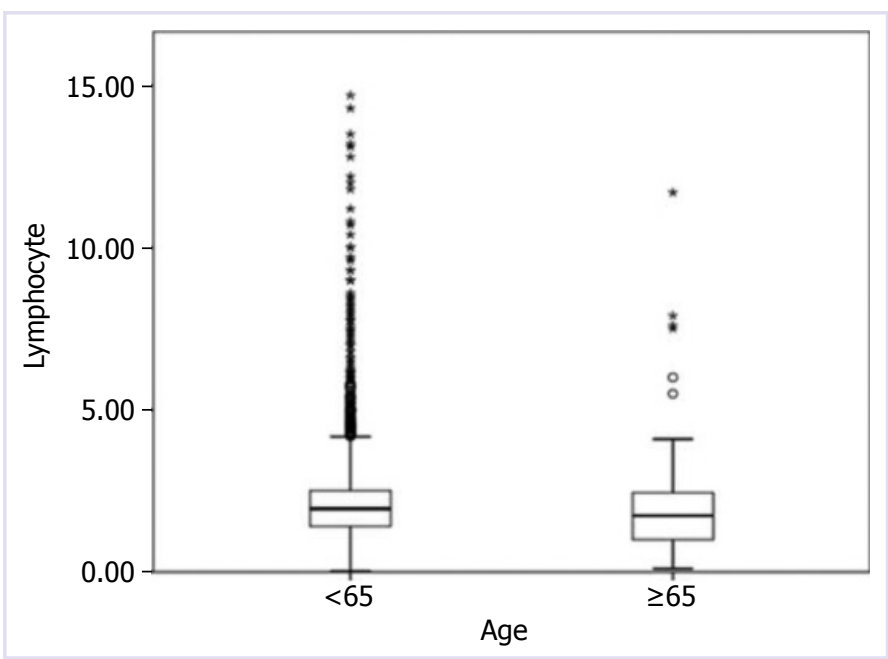

FIGURE 3. The comparison of lymphocyte counts between the age groups.

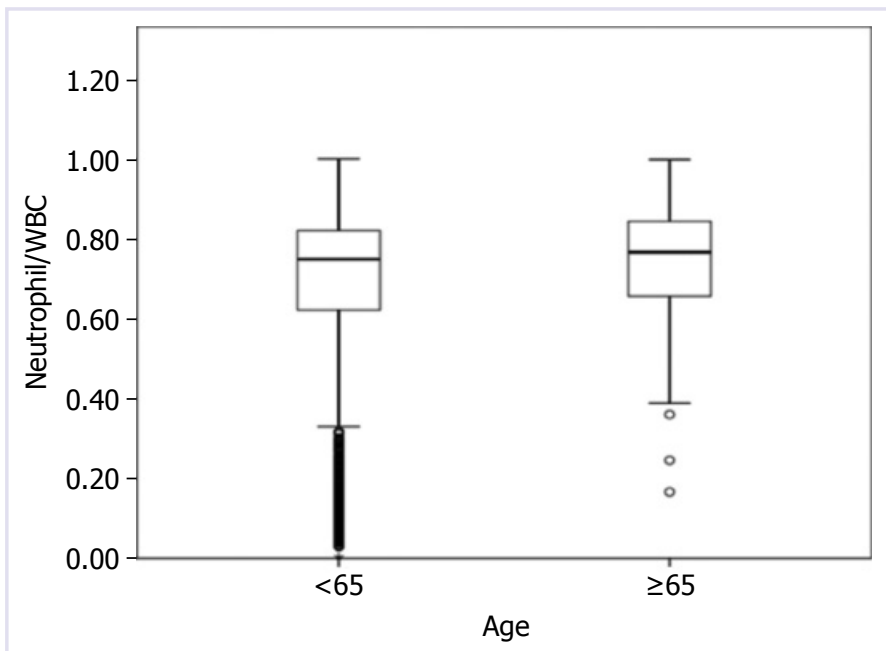

FIGURE 4. The distribution of NWR between the age groups.

geriatric patients, according to pathological results, with a significant difference between the age groups $(p=0.001)$ (Fig. 5). The demographic and clinical features of the patients are shown in Table 1.

The predictive values of the preoperative laboratory results of the patients were examined using a $\mathrm{ROC}$ analysis. At a cutoff value of $12.11 \times 10^{3} / \mu \mathrm{L}$ for $\mathrm{WBC}$, the specificity and sensitivity were $65.4 \%$ and $57.9 \%$, respectively, and the AUC was $0.632 \pm 0.024(\mathrm{p}<0.001)$. A ROC analysis with optimum cutoff values of NWR, lymphocyte, and MPV gave inadequate diagnostic accuracy; the AUC values were <0.6. The ROC analysis results for these laboratory parameters are shown in Table 2 and Figures 6-9. 


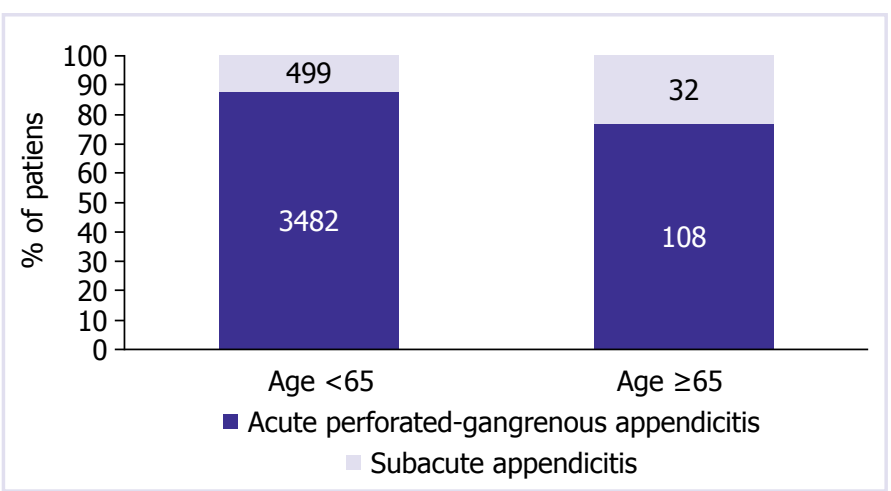

FIGURE 5. Pathological analysis according to the age groups.

\section{DISCUSSION}

Approximately half of the geriatric patients who present to the Emergency Depatment have abdominal pain complaints [24]. Intestinal obstruction and biliary diseases are the most common causes of acute abdomen in geriatric patients, followed by acute appendicitis [25]. The prognosis may be unfavorable, and geriatric patients may experience more complications compared to younger patients because their clinical signs of appendicitis may be atypical [26]. For example, this age group has increased perforation rates compared to younger patients, which may be associated with a diagnostic delay due to both late admission and a lack of classic signs and symptoms [27].

In our study, the geriatric group had a perforation ratio that was higher than in the non-geriatric group, but this difference was not statistically significant. An anal$y$ sis of the subgroups of perforated patients showed no statistically significant difference in the WBC values between geriatric and non-geriatric patients.

Higher rates of misdiagnosis (up to 50\%) are observed in the geriatric patient group, and some of those patients require more than a day to be diagnosed [27]. To improve the diagnostic accuracy in appendicitis, several scoring systems have been developed such as the Alvarado score that was first described in 1986 [28-34]. The Alvarado scoring system consists of several par-ameters including leukocytosis (WBC $>10 \times 10^{3} / \mu \mathrm{L}$ ) and neutrophil-toWBC ratio. Some other clinical features of the patients were also considered. Although there are several studies in the literature evaluating the accuracy of this scoring system in patients with appendicitis, there have been only a few studies that have only investigated the predictive role of preoperative laboratory parameters. Furthermore, studies of the predictive value of scoring systems and laboratory parameters are rare in older patients.

Inflammatory markers that emerge in acute appendicitis may change according to several factors, such as the bone marrow capacity, liver synthesis function, co-

TABLE 1. Demographic features and laboratory values of the patients

\begin{tabular}{lcccc} 
& $\begin{array}{c}\text { Age }<65 \\
\text { Median (Max.-Min.) }\end{array}$ & $\begin{array}{c}\text { Age } \geq 65 \\
\text { Median (Max.-Min.) }\end{array}$ & $\begin{array}{c}\text { Total } \\
\text { Median (Max.-Min.) }\end{array}$ & $p$ \\
\hline WBC & $13.70(41.80-2)$ & $11.70(26-4.86)$ & $13.60(41.80-2)$ & $<0.001$ \\
Neutrophil & $9.71(27.56-0.03)$ & $8.70(18.30-1)$ & $9.70(27.56-0.03)$ & 0.073 \\
NWR & $0.740(1-0)$ & $0.751(1-0)$ & $0.740(1-0)$ & 0.021 \\
Lymphocyte & $1.95(14.70-0.03)$ & $1.73(11.70-0.10)$ & $1.94(14.70-0.03)$ & 0.013 \\
NLR & $5.07(324-0.01)$ & $5.48(72-0.54)$ & $5.08(324-0.01)$ & 0.176 \\
Platelet & $247(789-20.90)$ & $232.50(533-38)$ & $247(789-20.90)$ & 0.072 \\
MPV & $8.30(18-0.10)$ & $8.40(11.50-5.90)$ & $8.30(18-0.10)$ & 0.036 \\
Bilirubin & $0.60(6.60-0.10)$ & $0.60(2.50-0.10)$ & $0.60(6.60-0.10)$ & 0.797 \\
Gender, $n$ (\%) & & & & \\
$\quad$ Female & $1502(37.51)$ & $72(51.43)$ & $1574(37.98)$ & 0.001 \\
$\quad$ Male & $2502(62.49)$ & $68(48.57)$ & $2570(62.02)$ & \\
Pathological analysis, $n$ (\%) & & & & \\
$\quad$ Sub-lymphoid hyperplasia & $499(12.53)$ & $32(22.86)$ & $531(12.89)$ & 0.001 \\
$\quad$ Acute-perforated-gangrenous appendicitis & $3482(87.47)$ & $108(77.14)$ & $3590(87.11)$ & \\
\hline
\end{tabular}

Max.: Maximum; Min.: Minimum. Mann Whitney U Test (Monte Carlo) - Pearson Chi-Square Test (Exact). 
TABLE2. Analysis for optimal cutoff values of predictive laboratory parameters

\begin{tabular}{ll}
\multicolumn{3}{c}{ Age $<65$} & \\
\hline $\mathrm{n}$ & $\%$
\end{tabular}

\begin{tabular}{ll} 
Age $\geq 65$ & \\
\hline $\mathrm{n}$ & $\%$
\end{tabular}

AUC \pm SE.

$\mathrm{p}$

\begin{tabular}{|c|c|c|c|c|c|c|}
\hline \multicolumn{7}{|l|}{ WBC } \\
\hline$>12.11$ & 2616 & $65.4 * *$ & 59 & 42.1 & \multirow[t]{2}{*}{$0.632 \pm 0.024$} & \multirow[t]{2}{*}{$<0.001$} \\
\hline$\leq 12.11$ & 1387 & 34.6 & 81 & $57.9 *$ & & \\
\hline \multicolumn{7}{|l|}{ NWR } \\
\hline$\leq 0.5449$ & 708 & $17.7^{* *}$ & 8 & 5.7 & \multirow[t]{2}{*}{$0.552 \pm 0.023$} & \multirow[t]{2}{*}{0.028} \\
\hline$>0.5449$ & 3293 & 82.3 & 132 & $94.3^{*}$ & & \\
\hline \multicolumn{7}{|l|}{ Lymphocyte } \\
\hline$>1.3$ & 3097 & $77.4 * *$ & 85 & 60.7 & \multirow[t]{2}{*}{$0.562 \pm 0.028$} & \multirow[t]{2}{*}{0.026} \\
\hline$\leq 1.3$ & 903 & 22.6 & 55 & $39.3^{*}$ & & \\
\hline \multicolumn{7}{|l|}{ MPV } \\
\hline$\leq 9.25$ & 3269 & $84.4 * *$ & 102 & 73.9 & \multirow[t]{2}{*}{$0.552 \pm 0.026$} & \multirow[t]{2}{*}{0.043} \\
\hline$>9.25$ & 602 & 15.6 & 36 & $26.1^{*}$ & & \\
\hline
\end{tabular}

AUC: Area under the ROC; WBC: White blood cell; MPV: Mean platelet volume. (Roc (Receiver Operating Curve) Analysis (Honley\&McNell - Youdenindex J).

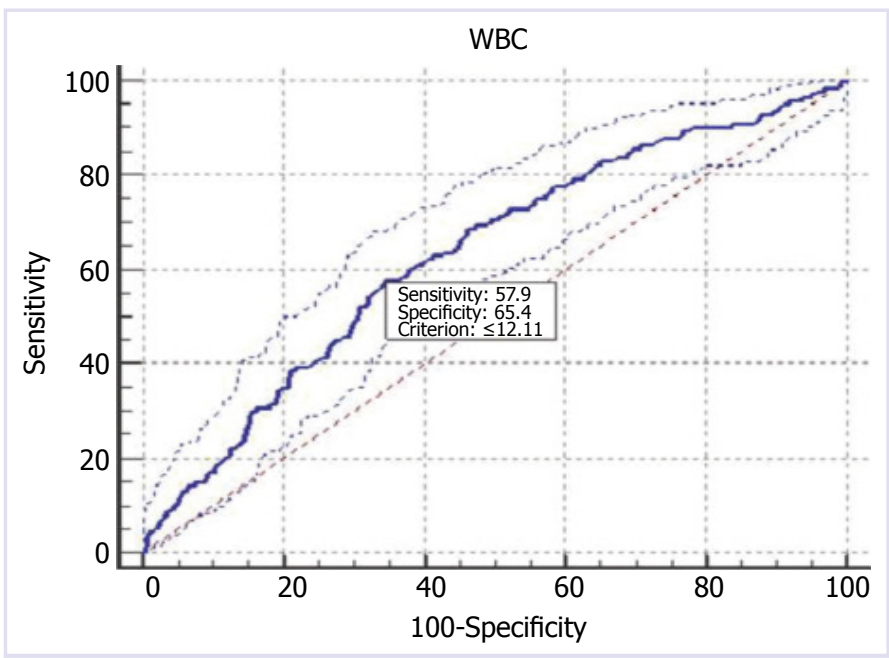

FIGURE6. Receiver operating characteristics (ROC) curve showing the predictive value for the white blood cell count (WBC).

morbidities, and drugs. The age of the patient is one of the most important factors affecting the degree of elevation in inflammatory markers. The WBC count is one of these inflammatory markers. Although there are many studies that have evaluated the benefits of using WBC, consensus has yet been reached [35].

Paajanen et al. investigated the preoperative WBC and C-reactive protein (CRP) levels of 6,000 patients consisting of all age groups including infants, children,

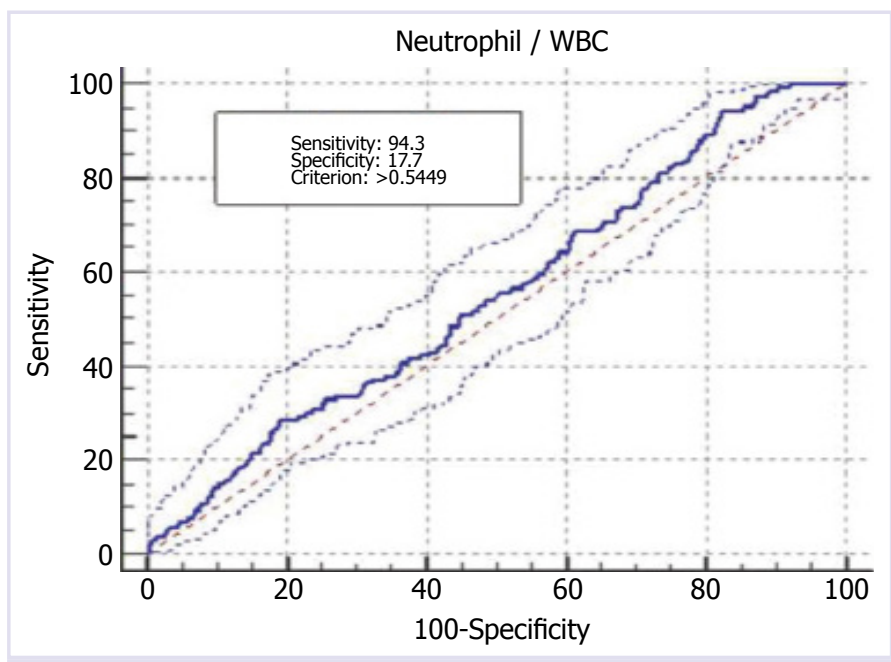

FIGURE 7. Receiver operating characteristics (ROC) curve showing the predictive value for NWR.

adolescents, adults, and geriatric patients [36]. A ROC analysis showed that WBC counts were better than CRP in suggesting the correct diagnosis in all age groups, except for those aged 0-5 years. However, systemic infections may generally result in less leukocytosis in geriatric patients, and some studies investigating infective endocarditis have shown a blunted leukocytosis response in older patients [37]. Acute appendicitis might also produce a very high degree of inflammation. Moreover, in 


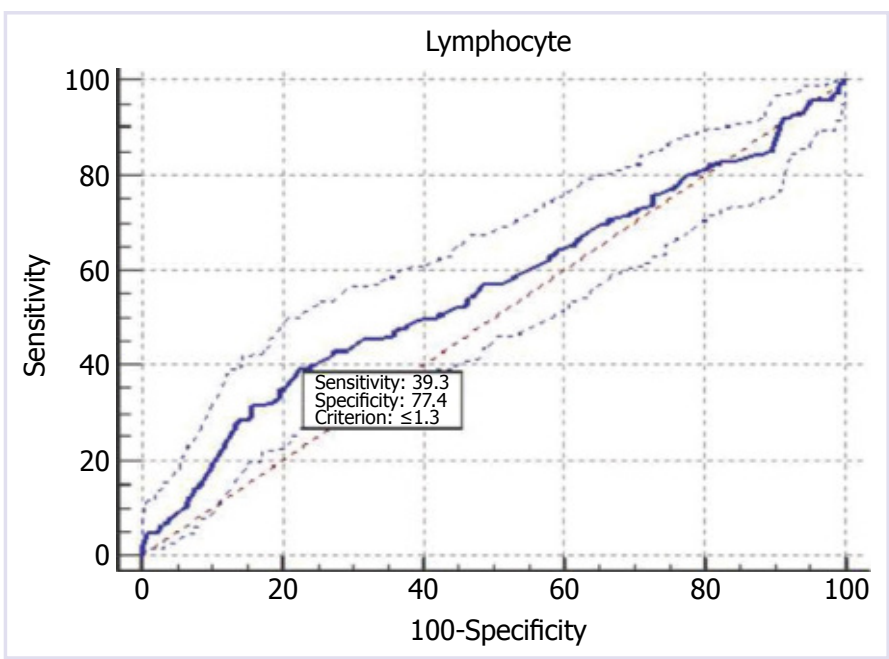

FIGURE 8. Receiver operating characteristics (ROC) curve showing the predictive value for lymphocytes.

geriatric patients, decreased production of WBC and CRP due to diminished capacity can hinder the prompt diagnosis of appendicitis [36]. Thus, geriatric patients have generally less remarkable inflammatory factors [38].

In this study, geriatric patients with appendicitis had lower WBC counts than the non-geriatric group. Increased WBC counts were also determined to be predictive in the geriatric group. Sevinc et al. analyzed 3392 patients undergoing appendectomy and classified the patients according to pathological examination: those with a normal appendix $(n=531)$ or with appendicitis $(n=2861)$ [38]. The optimum cutoff value for WBC was $11.9 \times 10^{3} /$ $\mu \mathrm{L}$, and a ROC analysis showed an AUC value $>0.6$. Therefore, elevated WBC levels $\left(>11.9 \times 10^{3} / \mu \mathrm{L}\right)$ were predictive of appendicitis with a positive predictive value of 0.92 . This study included all patients over the age of 15 years who underwent appendectomy. Styrud et al. investigated 47 patients aged $>80$ years who underwent appendectomy with a pre-diagnosis of appendicitis. They found higher complication rates in the older age group [39]. In contrast, they showed that the inflammatory parameters did not differ in the older group compared to the younger group. Therefore, elevated inflammatory markers were not associated with complications in the geriatric population.

Grönroos et al. [40] evaluated 83 patients who underwent abdominal surgery with a clinical diagnosis of acute appendicitis. Histopathological analysis of the surgical specimens revealed that 10 patients had a non-inflamed appendix, and the others had acute appendicitis. These two groups were compared in terms of preoperative $\mathrm{WBC}$ and CRP values, and analysis showed that



FIGURE9. Receiver operating characteristics (ROC) curve showing the predictive value for the mean platelet volume (MPV).

all patients with acute appendicitis had histopathologically confirmed elevated preoperative WBC and/or CRP levels. In that study, normal leukocyte counts and CRP excluded acute appendicitis with a predictive value of $100 \%$. Similar to our study, they showed that elevated leukocyte counts were an important finding for the prediction of acute appendicitis, but there was no examination of ROC curves or analysis of any cutoff values for the leukocyte counts.

The NWR is another important parameter to diagnose or predict complications in acute appendicitis. However, studies evaluating these patients generally consider the absolute neutrophil count rather than the NWR. Here higher NWR values were seen in geriatric patients compared to the non-geriatric group, but the diagnostic accuracy of NWR was inadequate $(\mathrm{AUC}<0.6)$. Jung et al. evaluated 103 geriatric patients with acute appendicitis [41], $56.3 \%$ of whom developed perforation; a ROC analysis was performed to identify the optimal cutoff values. The cutoff value for WBC was $10.6 \times 10^{3} /$ $\mu \mathrm{L}$. The odds ratio was 5.29 , and the AUC was 0.664 . The neutrophil count was predictive for perforation with a cutoff value of $8.1 \times 10^{3} / \mu \mathrm{L}$ (odds ratio of 4.776 ; AUC of 0.699).

The NWR is considered when calculating the "appendicitis inflammatory response" score, but the NWR was not analyzed with ROC analysis. Ayrik et al. compared 254 patients with appendicitis, 66 of whom had a normal appendix according to the postoperative pathological examination [42]. That study was not restricted to geriatric patients. The positive (PPV) and negative 
predictive values (NPV) of WBC were $88 \%$ and $33.3 \%$, respectively, in predicting the diagnosis of acute appendicitis $(A U C=0.660)$. The cutoff value for NWR was $>73$, and the PPV and NPV were $88.2 \%$ and $42.9 \%$ $(\mathrm{AUC}=0.701)$ for diagnosis of acute appendicitis. When differentiating complicated and uncomplicated appendicitis, a cutoff value of 78.51 for NWR was not statistically significant. A multiple logistic regression analysis showed that an increased NWR could increase the risk of uncomplicated and complicated appendicitis (OR 1.082 and 1.066, respectively). These results suggest that surgical treatment of acute appendicitis can be selected by considering NWR [42].

Yang et al. [43] showed that the NWR was higher in patients with acute appendicitis than in patients with a normal appendix in the geriatric population. In another study, NWR was shown to be higher in complicated appendicitis than in uncomplicated cases [44]. However, another study showed no significant differences for WBC or NWR between patients with perforated and non-perforated acute appendicitis [45]. Elangoven et al. [46] showed a very high predictive value and an increased percentage of band forms $(>6 \%)$ in predicting acute appendicitis in patients aged $\geq 60$ years. Leukocytosis also increased the specificity in that study.

In recent years, some hematological parameters such as NLR have gained importance in addition to classical blood counts. The NLR is a pro-inflammatory marker in some studies [47-49]. NLR is a simple, cheap, and effective biomarker. It has been widely investigated for predicting morbidity and mortality in inflammatory disorders, neoplastic diseases, and solid tumors [50-54]. Recent studies have suggested that the NLR can predict cardiovascular diseases and cancer [47-49]. The predictive value of NLR in acute appendicitis was first studied by Goodman et al. [55]. The NLR is more sensitive than the $\mathrm{WBC}$ count in predicting acute appendicitis.

Here, the NLR was higher in the non-geriatric group, but the difference was not significant. Cigsar et al. [56] investigated 755 patients who underwent surgery with a pre-diagnosis of appendicitis and grouped the patients as geriatric and non-geriatric. The patients were also grouped as positive or negative appendectomy according to postoperative pathological analysis. The NLR was higher in both the geriatric and non-geriatric patients with a positive appendectomy. The cutoff value of NLR was determined to be 4.90 with a sensitivity of $73.3 \%$ and specificity of $73.3 \%$. When the age, gender, and
NLR were analyzed together in the negative and positive appendectomy groups, the NLR could independently predict positive appendectomy $(\mathrm{p}<0.001)$.

Sevinc et al. also found NLR to be predictive for appendicitis with a positive predictive value of 0.89 in patients aged $>15$ years [38]. Jung et al. studied patients with acute appendicitis and found that the highest AUC value among inflammatory markers for predicting perforation was with NLR [41]. The NLR marker points to subclinical inflammation. It has been investigated in several studies including in patients with acute appendicitis [57]. Aydin et al. [58] investigated 195 patients with acute complicated or noncomplicated appendicitis. The cutoff values for WBC and NLR were $>13.8 \times 10^{3} / \mu \mathrm{L}$ (AUC=0.614) and $>4.87$ (AUC=0.641), respectively. The OR of WBC and NLR were calculated for complicated appendicitis (3.103 and 3.025, respectively). Other studies have compared the NLR in patients with acute appendicitis to those in patients with other acute abdominal pain. For example, increased WBC and NWR were found to be predictive for appendicitis in a study of renal colic and acute appendicitis [59].

MPV is another marker of inflammation. It has been broadly investigated in clinical studies. MPV reflects the platelet size and is part of a $\mathrm{CBC}$ analysis; however, practitioners often overlook its importance [60]. It can indicate inflammation and disease activity in several conditions including acute coronary syndromes, inflammatory bowel diseases, and pancreatitis [61]. It has been postulated that MPV is an inflammatory marker in severe inflammatory conditions-primarily acute appendicitis. Here, the MPV value was higher in geriatric patients with acute appendicitis than the non-geriatric group. However, this parameter had an inadequate value in predicting acute appendicitis-at an optimum cutoff value of 9.25, the AUC level was $<0.6$.

Previously, MPV levels in patients with acute appendicitis $(n=226)$ were found to be lower than normal [62]. However, contrasting results were also detected in other studies. Narci et al. [63] compared patients with acute appendicitis $(n=503)$ to a control group $(n=121)$. The MPV levels were statistically significantly higher in patients with acute appendicitis (median MPV $=7.92$ $\mathrm{fL}$ ) than the control group (median $\mathrm{MPV}=7.43 \mathrm{fL}$ ) $(p<0.001)$. The optimum cutoff value was $7.87 \mathrm{fL}$ according to the ROC analysis $(A U C=0.62)$. Studies on the predictive value of MPV in geriatric patients with acute appendicitis are limited. 
Bilirubin levels have been proposed to an appendicitis prediction tool. Although the value of hyperbilirubinemia for predicting severe appendicitis is well known [64], this parameter has not been used in routine clinical management. Some authors have suggested that bilirubin levels predict complicated appendicitis. However, in our study, there was no significant difference between the geriatric and non-geriatric groups according to bilirubin levels. In a study evaluating 103 geriatric patients with acute appendicitis, bilirubin was found to be predictive for perforation [41]. In that study, the cutoff value, odds ratio, and AUC values for total bilirubin were $0.7 \mathrm{mg} / \mathrm{dL}$, 4.41 , and 0.646 , respectively. Further studies are needed in geriatric patients to evaluate the predictive value of bilirubin in appendicitis.

There is no single symptom or clinical sign, laboratory test, or radiological finding to make a precise diagnosis of acute appendicitis. It is absolutely necessary to consider all clinical and laboratory findings, as well as the radiological methods for diagnosing acute appendicitis. Further studies are required to clearly define the predictive values of inflammatory markers in geriatric patients with acute appendicitis.

In conclusion, the results showed that WBC and lymphocyte counts as well as the NLR were higher in the nongeriatric group. The NWR and MPV were higher in the geriatric group. The $\mathrm{WBC}$ counts $>12.11 \times 10^{3} / \mu \mathrm{L}$ were predictive for acute appendicitis in the geriatric group.

Ethics Committee Approval: This study, which was approved by the ethical board of the Istanbul Training and Research Hospital (09/22/2017-1090).

Conflict of Interest: No conflict of interest was declared by the authors.

Financial Disclosure: The authors declared that this study has received no financial support.

Authorship Contributions: Concept - CT, SB; Design - SB, EC; Supervision - EK, MMS; Materials - EC, MMS; Data collection and/or processing - SC, MMS, EC; Analysis and/or interpretation - BG, CT; Writing - CT, SB; Critical review - KT, MEG.

\section{REFERENCES}

1. Williams GR. Presidential Address: a history of appendicitis. With anecdotes illustrating its importance. Ann Surg 1983;197:495-506.

2. Fitz RH. Perforating inflammation of the vermiform appendix with special reference to its early diagnosis and treatment. Am J Med Sci 1886;92:321.

3. Gürleyik G, Gürleyik E. Age-related clinical features in older patients with acute appendicitis. Eur J Emerg Med 2003;10:200-3. [CrossRef]

4. Addiss DG, Shaffer N, Fowler BS, Tauxe RV. The epidemiology of appendicitis and appendectomy in the United States. Am J Epidemiol 1990;132:910-25. [CrossRef]

5. Pittman-Waller VA, Myers JG, Stewart RM, Dent DL, Page CP, Gray GA, et al. Appendicitis: why so complicated? Analysis of 5755 consecutive appendectomies. Am Surg 2000;66:548-54.

6. SCOAP Collaborative, Cuschieri J, Florence M, Flum DR, Jurkovich GJ, Lin P, Steele SR, et al. Negative appendectomy and imaging accuracy in the Washington State SurgicalCare and Outcomes Assessment Program. Ann Surg 2008;248:557-63.

7. Körner H, Söndenaa K, Söreide JA, Andersen E, Nysted A, Lende $\mathrm{TH}, \mathrm{Kjellevold} \mathrm{KH}$. Incidence of acute nonperforated and perforated appendicitis: age-specific and sex-specific analysis. World J Surg 1997;21:313-7. [CrossRef]

8. Nmadu PT. Appendicitis in older African patients: 10 year review and report of 84 cases. Cent Afr J Med 1995;41:196-9.

9. Watters JM, Blakslee JM, March RJ, Redmond ML. The influence of age on the severity of peritonitis. Can J Surg 1996;39:142-6.

10. Horattas MC, Guyton DP, Wu D. A reappraisal of appendicitis in the elderly. Am J Surg 1990;160:291-3. [CrossRef]

11. Lunca S, Bouras G, Romedea NS. Acute appendicitis in the elderly patient: diagnostic problems, prognostic factorsand outcomes. Rom J Gastroenterol 2004;13:299-303.

12. Sülberg D, Chromik AM, Kersting S, Meurer K, Tannapfel A, Uhl W, et al. Appendicitis in the elderly. CRP value as decision support for diagnostic laparoscopy. [Article in German]. Chirurg 2009;80:608-14.

13. Hui TT, Major KM, Avital I, Hiatt JR, Margulies DR. Outcome of elderly patients with appendicitis: effect of computed tomography and laparoscopy. Arch Surg 2002;137:995-8. [CrossRef]

14. Faiz O, Clark J, Brown T, Bottle A, Antoniou A, Farrands P, et al. Traditional and laparoscopic appendectomy in adults: outcomes in English NHShospitals between 1996 and 2006. Ann Surg 2008;248:800-6.

15. Sporn E, Petroski GF, Mancini GJ, Astudillo JA, Miedema BW, Thaler K. Laparoscopic appendectomy-is it worth the cost? Trend analysis in the US from 2000 to 2005. J Am Coll Surg 2009;208:179-85.e2. [CrossRef]

16. Guller U, Hervey S, Purves H, Muhlbaier LH, Peterson ED, Eubanks $\mathrm{S}$, et al. Laparoscopic versus open appendectomy: outcomes comparison based on a largeadministrative database. Ann Surg 2004;239:43-52.

17. Şahbaz NA, Bat O, Kaya B, Ulukent SC, İlkgül Ö, Özgün MY, et al. The clinical value of leucocyte count and neutrophil percentage in diagnosing uncomplicated (simple) appendicitis and predicting complicated appendicitis. Ulus Travma Acil Cerrahi Derg 2014;20:423-6. [CrossRef]

18. Markar SR, Karthikesalingam A, Falzon A, Kan Y. The diagnostic value of neutrophil: lymphocyte ratio in adults with suspected acute appendicitis. Acta Chir Belg 2010;110:543-7. [CrossRef]

19. Ishizuka M, Shimizu T, Kubota K. Neutrophil-to-lymphocyte ratio has a close association with gangrenousappendicitis in patients undergoing appendectomy. Int Surg 2012;97:299-304. [CrossRef]

20. Tanrikulu CS, Tanrikulu Y, Sabuncuoglu MZ, Karamercan MA, Akkapulu N, Coskun F. Mean platelet volume and red cell distribution width as a diagnostic marker in acute appendicitis. Iran Red Crescent Med J 2014;16:e10211. [CrossRef]

21. Farooqui W, Pommergaard HC, Burcharth J, Eriksen JR. The diagnostic value of a panel of serological markers in acute appendicitis. Scand J Surg 2015;104:72-8, [CrossRef]

22. Hong YR, Chung CW, Kim JW, Kwon CI, Ahn DH, Kwon SW, et al. Hyperbilirubinemia is a significant indicator for the severity of acute appendicitis. J Korean Soc Coloproctol 2012;28:247-52. [CrossRef]

23. Yeh EL, McNamara RM. Abdominal pain. Clin Geriatr Med 2007;23:255-70. [CrossRef]

24. Fagbohun CF, Toy EC, Baker B. The evaluation of acute abdominal pain in the elderly patient. Prim Care Update Ob/Gyns 1999;6ः181-5. 
25. Franz MG, Norman J, Fabri PJ. Increased morbidity of appendicitis with advancing age. Am Surg 1995;61:40-4.

26. Storm-Dickerson TL, Horattas MC. What have we learned over the past 20 years about appendicitis in the elderly? Am J Surg 2003;185:198-201. [CrossRef]

27. Alvarado A. A practical score for the early diagnosis of acute appendicitis. Ann Emerg Med 1986;15:557-64. [CrossRef]

28. Ohmann C, Yang Q, Franke C. Diagnostic scores for acute appendicitis. Abdominal Pain Study Group. Eur J Surg 1995;161:273-81.

29. van den Broek WT, Bijnen BB, Rijbroek B, Gouma DJ. Scoring and diagnostic laparoscopy for suspected appendicitis. Eur J Surg 2002;168:349-54. [CrossRef]

30. Fenyö G, Lindberg G, Blind P, Enochsson L, Oberg A. Diagnostic decision support in suspected acute appendicitis: validation of a simplified scoring system. Eur J Surg 1997;163:831-8.

31. Christian F, Christian GP. A simple scoring system to reduce the negative appendicectomy rate. Ann R Coll Surg Engl 1992;74:281-5.

32. Lintula H, Pesonen E, Kokki H, Vanamo K, Eskelinen M. A diagnostic score for children with suspected appendicitis. Langenbecks Arch Surg 2005;390:164-70. [CrossRef]

33. Keskek M, Tez M, Yoldas O, Acar A, Akgul O, Gocmen E, et al. Receiver operating characteristic analysis of leukocyte counts in operations for suspected appendicitis. Am J Emerg Med 2008;26:769-72.

34. Baidya N, Rodrigues G, Rao A, Khan S. Evaluation Of Alvarado Score In Acute Appendicitis: A Prospective Study. The Internet J Surg. 2006;9:1. [CrossRef]

35. Cardall T, Glasser J, Guss DA. Clinical value of the total white blood cell count and temperature in the evaluation of patients with suspected appendicitis. Acad Emerg Med 2004;11:1021-7. [CrossRef]

36. Paajanen H, Mansikka A, Laato M, Kettunen J, Kostiainen S. Are serum inflammatory markers age dependent in acute appendicitis? J Am Coll Surg 1997;184:303-8.

37. Ellis G, Whitehead MA, O'Neill D, Langhorne P, Robinson D. Comprehensive geriatric assessment for older adults admitted to hospital. Cochrane Database Syst Rev 2011:CD006211. [CrossRef]

38. Sevinç MM, Kınacı E, Çakar E, Bayrak S, Özakay A, Aren A, et al. Diagnostic value of basic laboratory parameters for simple and perforated acute appendicitis: an analysis of 3392 cases. Ulus Travma Acil Cerrahi Derg 2016;22:155-62. [CrossRef]

39. Styrud J, Eriksson S. Acute appendicitis in the elderly. An analysis of 47 patients over 80 years of age. Int J Surg Investig 1999;1:297-300.

40. Grönroos JM. Is there a role for leukocyte and CRP measurements in the diagnosis of acute appendicitis in the elderly? Maturitas 1999;31:255-8. [CrossRef]

41. Jung SK, Rhee DY, Lee WJ, Woo SH, Seol SH, Kim DH, Choi SP. Neutrophil-to-lymphocyte count ratio is associated with perforated appendicitis in elderly patients of emergency department. Aging Clin Exp Res. 2017 Jun;29(3):529-536. [CrossRef]

42. Ayrık C, Karaaslan U, Dağ A, Bozkurt S, Toker İ, Demir F. Predictive calue of leucocyte count, neutrophil percent and C-reactive proteinconcentration "cut-off value" on the diagnosis of appendicitis. Ulus Travma Acil Cerrahi Derg 2016;22:76-83. [CrossRef]

43. Yang HR, Wang YC, Chung PK, Chen WK, Jeng LB, Chen RJ. Role of leukocyte count, neutrophil percentage, and $\mathrm{C}$-reactive protein in the diagnosis of acute appendicitis in the elderly. Am Surg 2005;71:344-7.

44. Yang HR, Wang YC, Chung PK, Chen WK, Jeng LB, Chen RJ. Laboratory tests in patients with acute appendicitis. ANZ J Surg 2006;76:71-4.

45. Sirikurnpiboon S, Amornpornchareon S. Factors Associated with Perforated Appendicitis in Elderly Patients in a TertiaryCare Hospital. Surg Res Pract 2015;2015:847681. [CrossRef]
46. Elangovan S. Clinical and laboratory findings in acute appendicitis in the elderly. J Am Board Fam Pract 1996;9:75-8.

47. Wang J, Jia Y, Wang N, Zhang X, Tan B, Zhang G, et al. The clinical significance of tumor-infiltrating neutrophils and neutrophil-to-CD8+ lymphocyte ratio in patients with resectable esophageal squamous cell carcinoma. J Transl Med 2014;12:7. [CrossRef]

48. Xue P, Kanai M, Mori Y, Nishimura T, Uza N, Kodama Y, et al. Neutrophil-to-lymphocyte ratio for predicting palliative chemotherapy outcomes in advanced pancreatic cancer patients. Cancer Med 2014;3:406-15. [CrossRef]

49. Wang X, Zhang G, Jiang X, Zhu H, Lu Z, Xu L. Neutrophil to lymphocyte ratio in relation to risk of all-cause mortality and cardiovascular events among patients undergoing angiography or cardiac revascularization: a meta-analysis of observational studies. Atherosclerosis 2014;234:206-13. [CrossRef]

50. Bozbay M, Uyarel H. Neutrophil-to-lymphocyte ratio: A novel and simple prognostic marker for infective endocarditis. J Crit Care 2015;30:822. [CrossRef]

51. Graziosi L, Marino E, De Angelis V, Rebonato A, Cavazzoni E, Donini A. Prognostic value of preoperative neutrophils to lymphocytes ratio in patients resected for gastric cancer. Am J Surg 2015;209:333-7. [CrossRef]

52. Seretis C, Gourgiotis S, Gemenetzis G, Seretis F, Lagoudianakis E, Dimitrakopoulos G. The significance of neutrophil/lymphocyte ratio as a possible marker of underlying papillary microcarcinomas in thyroidal goiters: a pilot study. Am J Surg 2013;205:691-6. [CrossRef]

53. Chen J, Deng Q, Pan Y, He B, Ying H, Sun H, et al. Prognostic value of neutrophil-to-lymphocyte ratio in breast cancer. FEBS Open Bio 2015;5:502-7. [CrossRef]

54. Paramanathan A, Saxena A, Morris DL. A systematic review and metaanalysis on the impact of pre-operative neutrophil lymphocyte ratio on long term outcomes after curative intent resection of solid tumours. Surg Oncol 2014;23:31-9. [CrossRef]

55. Goodman DA, Goodman CB, Monk JS. Use of the neutrophil:lymphocyte ratio in the diagnosis of appendicitis. Am Surg 1995;61:257-9.

56. Cigsar G, Yildirim AC, Anuk T, Guzel H, Gunal E, Gulkan S, et al. Neutrophil to Lymphocyte Ratio on Appendectomy of Geriatric and Nongeriatric Patients. J Invest Surg 2017;30:285-90. [CrossRef]

57. Yavuz E, Ercetin C, Uysal E, Solak S, Biricik A, Yigitbas H, et al. Diagnostic Value of neutrophil/Lymphocyte ratio in geriatric cases with appendicitis. Turk J Geriatrics 2014;17:345-9.

58. Aydin OU, Soylu L, Dandin O, Uysal Aydin E, Karademir S. Laboratory in complicated appendicitis prediction and predictive value of monitoring. Bratisl Lek Listy 2016;117:697-701. [CrossRef]

59. Acar E, Özcan Ö, Deliktaş H, Beydilli H, Kırlı İ, Alataş ÖD, et al. Laboratory markers has many Valuable Parameters in the discrimination between acute appendicitis and renal colic. Ulus Travma Acil Cerrahi Derg 2016;22:17-22. [CrossRef]

60. Sandhaus LM, Meyer P. How useful are $\mathrm{CBC}$ and reticulocyte reports to clinicians? Am J Clin Pathol 2002;118:787-93. [CrossRef]

61. Beyazit Y, Sayilir A, Torun S, Suvak B, Yesil Y, Purnak T, et al. Mean platelet volume as an indicator of disease severity in patients with acute pancreatitis. Clin Res Hepatol Gastroenterol 2012;36:162-8. [CrossRef]

62. Albayrak Y, Albayrak A, Albayrak F, Yildirim R, Aylu B, Uyanik A, et al. Mean platelet volume: a new predictor in confirming acute appendicitis diagnosis. Clin Appl Thromb Hemost 2011;17:362-6. [CrossRef]

63. Narci H, Turk E, Karagulle E, Togan T, Karabulut K. The role of mean platelet volume in the diagnosis of acute appendicitis: a retrospective casecontrolled study. Iran Red Crescent Med J 2013;15:e11934. [CrossRef]

64. Miller DF, Irvine RW. Jaundice in acute appendicitis. Lancet 1969;94:201-6. 